\title{
Protective effects of aloe vera gel (aloe baberdensis Miller) on aluminum chloride-induced reproductive toxicity in male Wistar rats
} \author{
Christiana Faleye ${ }^{2}$ \\ ${ }^{1}$ Department of Human Anatomy, Federal University of Technology, Akure. Nigeria \\ ${ }^{2}$ Department of Chemical Science, Joseph Ayo Babalola University, Ikeji-Arakeji. Nigeria
}

Busuyi Kolade Akinola, ${ }^{1}$ Toluwase Solomon Olawuyi ${ }^{1}$, Victor Okoliko Ukwenya ${ }^{1}$, Lekia Damilola Daniel ${ }^{1}$, Bolanle

\begin{abstract}
Objective: This study aims at investigating the protective effects of aloe vera gel on aluminum chlorideinduced testicular toxicity of adult Wistar rats.

Methods: Twenty male Wistar rats were randomly divided into four groups (A, B, C, and D) with five animals per group. Group $A$ serves as the control group and received distilled water $(1 \mathrm{ml} / \mathrm{Kg})$. Group $B$ received distilled water $(1 \mathrm{ml} / \mathrm{Kg})$ with $100 \mathrm{mg} / \mathrm{kg}$ b.wt of aluminum chloride daily. Group C received $100 \mathrm{mg} / \mathrm{kg}$ b.wt of aluminum chloride with $600 \mathrm{mg} / \mathrm{kg}$ b.wt of Aloe vera gel daily. Group $D$ received $100 \mathrm{mg} / \mathrm{kg}$ b.wt of aluminum chloride with $5 \mathrm{mg} / \mathrm{kg}$ b.wt of vitamin C daily. The animals were fed on standard laboratory animal diet and water ad libitum. Administration was via oral cannula for four weeks. The rats were slaughtered using cervical dislocation. The testes were harvested for seminal, biochemical and histological analysis.

Results: The results demonstrate that the administration of aloe vera gel (AVG) is capable of preventing testicular toxicity due to aluminum chloride. Aluminum chloride caused a significant change in the testes and seminal parameters of group $B$ when compared to the control animals. The level of Nitric oxide (NO) increased and the level of Superoxide dismutase (SOD) decreased significantly in rats treated with aluminum chloride.

Conclusions: The administration of aloe vera gel showed a preventive response in aluminum-induced testicular toxicity of rats as evidenced by histological and biochemical analysis.
\end{abstract}

Keywords: Testis, aloe vera gel, aluminum chloride, semen

\section{INTRODUCTION}

Male infertility caused by exposure to heavy metals is a global problem [Wong and Cheng, 2011], and it accounts for $45 \%$ of infertility cases (Kumar \& Singh, 2015). Testicular toxicity, an injury to the testis, is associated with impaired testicular function caused by free radicals derived from oxygen on exposure to drugs, chemicals and noninfectious agents (Liu et al., 2017). A report has confirmed that oxidative stress is the chief cause of testicular toxicity (Gupta \& Verma, 2018).

Aluminum is a trivalent cation found in its ionic form in most animals, plants and in natural waters everywhere (Jiang et al., 2008). Aluminum enters the human body via food, water, drugs, air, aluminum ware and containers, as well as in many manufactured food stuffs, such as processed cheese, baking powders, cake mixes, pancake mixes, frozen dough (Nayak, 2002). Moreover, high concentrations of aluminum in spermatozoa and seminal plasma of humans decreases sperm viability and motility
(Yousef et al., 2007). Guo et al. (2002) described the oxidative damage and testicular toxicity caused by aluminum to the reduction in testis acetylcholinesterase (AChE) activity. Testicular aluminum buildup, necrosis of spermatocytes/spermatids, and a significant decline in fertility were also detected in both male rats and mice (Guo et al., 2005a, Sharma et al., 2003). Aluminum may cause male reproductive toxicity through different mechanisms such as inducing oxidative stress, interfering with spermatogenesis and steroidogenesis, damaging cell signaling, disrupting the blood-testis barrier, and affecting the endocrine system (Pandey \& Jain, 2013). Aluminum has also been stated to cause testicular toxicity by increasing nitric oxide level (Guo et al., 2005b). Another study showed that aluminum reduces antioxidants and increases lipid peroxidation (Yousef \& Salama, 2009).

Humankind has used aloe vera for thousands of years in folk medicine for therapeutic properties, especially on the skin. This plant is one of the oldest known medicinal plants, and its first documented use by humans dates back to an Egyptian papyrus from 3,500 BC (Crosswhite \& Crosswhite, 1984). Moreover, modern clinical use began in the 1930 s with reports of successful treatment of x-ray and radium burns (Surjushe et al., 2008). The leaves are composed of three layers: an inner gel, a yellow sap and the outer thick layer of $15-20$ cells called 'rind' (Eshun \& He, 2004). When the whole leaf of Aloe vera is used, it is difficult to distinguish whether its biological effects are attributed to the gel or the latex because, during the gel preparation, exudates compounds may infiltrate (Reynolds \& Dweck, 1999). The phytochemical analysis of Aloe vera gel shows that it has the following compounds; polysaccharides, steroids, organic acids, antibiotic agents, amino acids and minerals, which has skin soothing and cells protecting effects (Hamman, 2008). Different studies reported the hypoglycemic, hypotensive, liver protective and blood purifying properties of Aloe vera (Hamman 2008; Nwajo, 2006). This study investigates the protective effects of Aloe vera leaf gel (aloe baberdensis Miller) on aluminum chloride-induced testicular toxicity of male Wistar rats.

\section{MATERIALS AND METHODS}

\section{Experimental animals}

We used twenty male Wistar rats weighing between $120-140 \mathrm{~g}$ for this study. The rats were obtained from the Central animal facility of the Biochemistry Department, Federal University of Technology Akure, Ondo State, Nigeria. The rats were kept in ventilated cages at optimum temperature and 12 hours light/dark cycles. The animals were fed on standard laboratory animal diet and water ad libitum. The experiment was carried out in accordance with current rules and guidelines that have been established for the care of laboratory animals (National Research Council, 2011). The rats were acclimatized for two weeks before the commencement of the experiment. 
Preparation of aloe barbadensis leaf gel

Healthy and mature Aloe vera leaves were harvested from the Botanical garden of the Federal University of Technology, Akure, Ondo State, Nigeria. The leaves were washed with clean water, the thick epidermis was peeled off and the aloe vera gel was removed carefully. The gel was then homogenized with an electric blender. The homogenate was concentrated by filtration using whattman's filter paper size 2 . The thickened concentrated gel and the filtrate were kept at $4^{\circ} \mathrm{C}$ until used.

\section{Experimental design}

The 20 male Wistar rats were randomly divided into 4 groups (, , B , C, and D) with five animals per group.

Group A served as the control group and received oral administration of distilled water $(1 \mathrm{ml} / \mathrm{Kg} \mathrm{b}$.wt) daily for 4 weeks.

Group B received oral administration of distilled water ( $1 \mathrm{ml} / \mathrm{Kg} \mathrm{b.wt)}$ with $100 \mathrm{mg} / \mathrm{kg} \mathrm{b.wt} \mathrm{of} \mathrm{aluminum} \mathrm{chloride}$ daily for 4 weeks.

Group C received oral administration of $100 \mathrm{mg} / \mathrm{kg}$ b.wt of aluminum chloride with $600 \mathrm{mg} / \mathrm{kg}$ b.wt of Aloe vera gel daily for 4 weeks.

Group D received oral administration of $100 \mathrm{mg} / \mathrm{kg}$ b.wt of aluminum chloride with $5 \mathrm{mg} / \mathrm{kg}$ b.wt of vitamin C daily for 4 weeks.

At the end of the experiment, the animals were slaughtered using cervical dislocation and the testes removed for histological analysis.

\section{Histological procedures}

The testes were excised and immediately fixed in bouin's fluid, and thereafter processed routinely for paraffin embedding; Micro-sections of $5 \mu \mathrm{m}$ were obtained with a rotary microtome and processed with Hematoxylin and Eosin stain (H\&E). We examined the stained slides under a microscope using different magnifications (X40 and X100) and took photomicrographs.

\section{Semen Analysis}

The cauda epididymis was removed, incised and semen prepared for analysis. Sperm count was done according to the method reported by Ekaluo et al. (2008). The sperm viability test was determined using the Eosin-Nigrosin staining technique (Bjorndahl et al., 2003). Sperm head abnormality test was done according to Ekaluo et al. (2009). Sperm motility and $\mathrm{pH}$ were done as reported by Ekaluo et al. (2008).

\section{Biochemical analysis}

The testes were excised and homogenized in $0.1 \mathrm{mmol} / \mathrm{L}$ Tris buffer $(\mathrm{pH}$ 7.4) and used for the biochemical estimations. From the left testis, homogenates were subjected to a biochemical assay to estimate the superoxide dismutase (SOD) activity by the method described by Misra \& Fridovich (1972). Nitric oxide (NO) in the tissue was assayed according to the method by Moshage et al. (1995). This was done to evaluate the effect of AVG on oxidative stress markers and to validate the claim that aluminum chloride causes testicular toxicity by inducing oxidative stress.

\section{Statistical analysis}

Using Graph pad prism (version 8.0.), the data obtained was analyzed and expressed as mean \pm S.E.M (standard error of mean) and subjected to one-way analysis of variance (ANOVA). This was then subjected to a posthoc test using the student Neumann Keul's method and values were considered statistically significant if $p<0.05$.

\section{RESULTS}

Histological sections of testes across the group

Plates 1 and 2 show the results. The photomicrograph of the Group C's histological section revealed that the administration of Aloe Vera gel (AVG) ameliorates the cytoarchitecture and histomorphological distortions evident
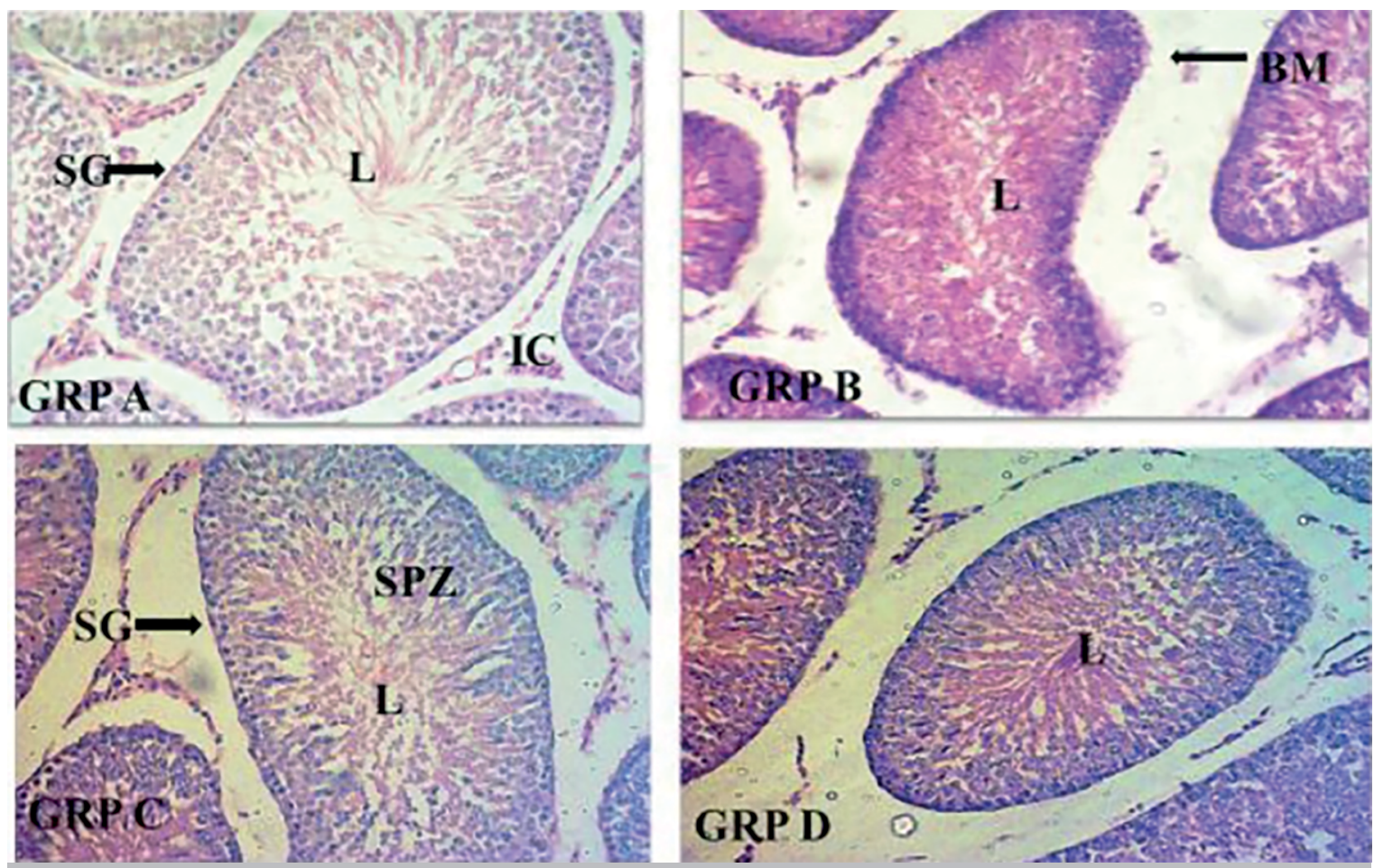

Plate 1. Photomicrograph of testes showing: Group A with normal histological architecture characterized by typically organized layers of spermatogenic cells; Group B with distorted tubular architecture and disorganization of the spermatogenic cells in seminiferous tubules and major pathological changes in the lumen (L); Group $\mathrm{C}$ with restored microarchitecture of the testicular morphology, distribution of epithelial lining, partially restored lumen (L); Group D with restored microarchitecture of the testicular morphology, distribution of epithelial lining, partially restored lumen (L). Stains: Hematoxylin and Eosin (H\&E). Magnification X100. 

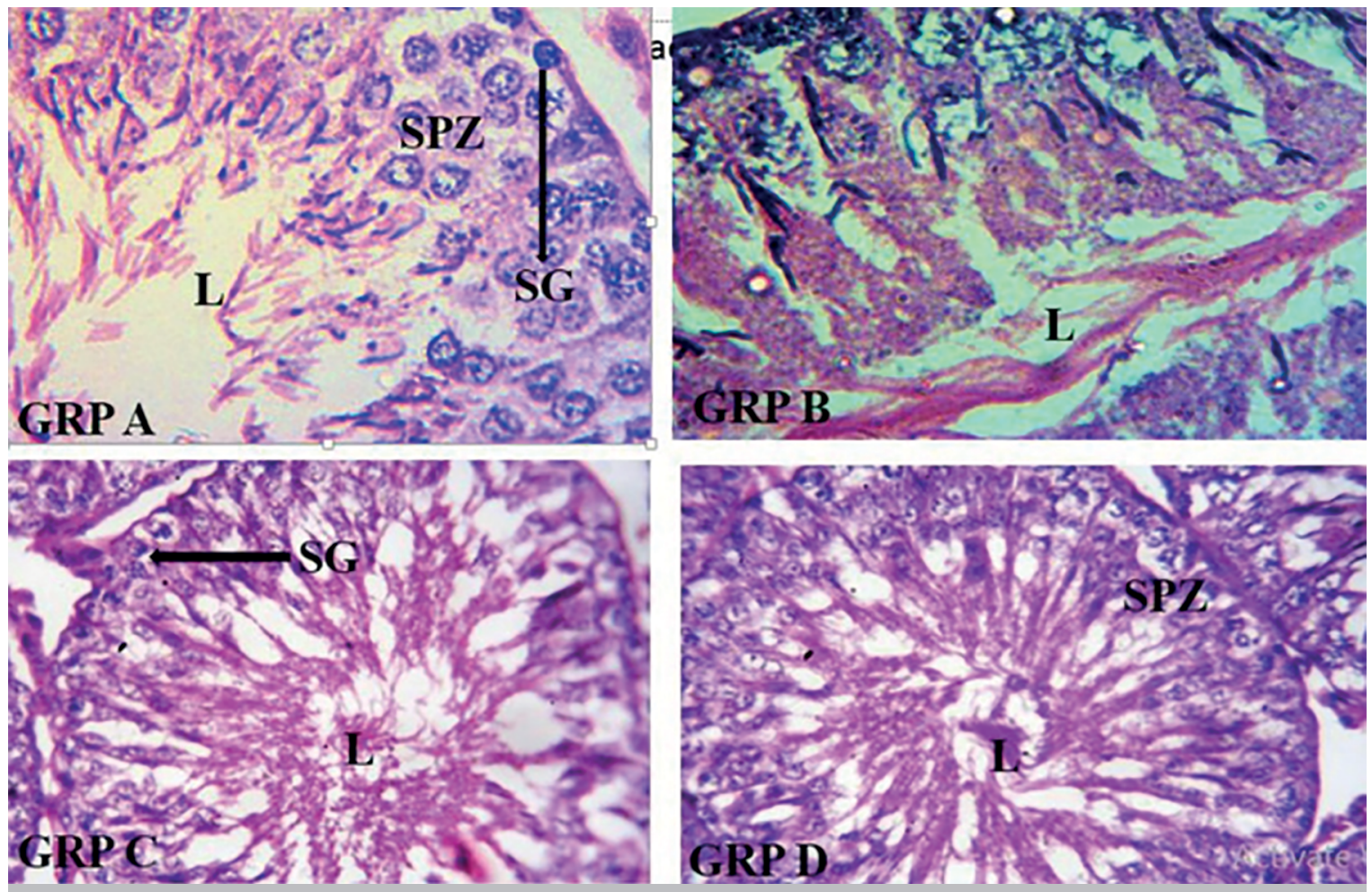

Plate 2. Photomicrograph of testes histological architecture showing: Group A with normal histological architecture characterized by typically organized layers of spermatogenic cells; Group B with distorted tubular architecture and disorganization of the spermatogenic cells in seminiferous tubules, major pathological changes in the lumen (L); Group $C$ with restored microarchitecture of the testicular morphology, distribution of epithelial lining, partially restored lumen (L); Group D with restored microarchitecture of the testicular morphology, distribution of epithelial lining, partially restored lumen (L). Stains: Hematoxylin and Eosin (H\&E). Magnification X400.

in group $\mathrm{B}$ (induced with $\mathrm{AlCl}_{3}$ ). The observations of the control group $(A)$, showed normal testicular morphology. This is in complete contrast to group $B$, which showed a structural distortion typical of testicular toxicity. Group D also shows that Vitamin $\mathrm{C}$ has a similar effect on $\mathrm{AlCl}_{3}-$ induced testicular toxicity when compared with the group treated with AVG.

\section{Superoxide dismutase (SOD)}

Figure 1 illustrates the effects of Aloe vera gel on SOD activity in the serum of Wistar rats with Aluminum chlorideinduced testicular toxicity. Group A (control) presented an average concentration of SOD of $0.14 \pm 0.04 \mathrm{U} / \mathrm{L}$. Group B presented an average concentration of SOD of $0.04 \pm 0.02 \mathrm{U} / \mathrm{L}$. Group C presented an average SOD concentration of $0.17 \pm 0.02 \mathrm{U} / \mathrm{L}$ while group $D$ presented an average concentration of $0.16 \pm 0.01 \mathrm{U} / \mathrm{L}$. There was a significant decrease $(p<0.001)$ in the serum level of SOD in group $B$ rats when compared with the normal controls (group A). The serum level of SOD is also significantly different when comparing the treated groups with the non-treated group (group B) $(p<0.005)$. There was no significant difference between the treated groups when compared to each other.

\section{Nitric oxide (NO)}

Figure 2 illustrates the effects of Aloe vera gel on the Nitric oxide (NO) activity in the serum of Wistar rats with Aluminum chloride-induced testicular toxicity. Group A (control) presented an average concentration of NO of $108.4 \pm 9.0 \mathrm{mmol} / \mathrm{mg}$ protein. Group B presented an average concentration of $\mathrm{NO}$ of $219.7 \pm 29.2 \mathrm{mmol} / \mathrm{mg}$ protein. Group C presented an average concentration of
NO of $61.4 \pm 3.3 \mathrm{mmol} / \mathrm{mg}$ protein; while group $D$ presented an average concentration of $38.4 \pm 5.9 \mathrm{mmol} / \mathrm{mg}$ protein. There was a significant increase $(p<0.005)$ in the serum level of NO in group $B$ rats when compared with the normal controls (group A). The serum level of NO is also significantly different when comparing the treated groups with the non-treated group (group B) $(p<0.001)$.

\section{Semen analysis}

\section{Sperm volume}

There was an increase in sperm volume among the rats in the group treated with Aloe vera gel (group $\mathrm{C}$ ) when compared with the control group. Group B shows a decrease in the sperm volume when compared with the control group (Figure 3 ).

\section{Sperm motile count}

This increased significantly $(p<0.05)$ in the group treated with Aloe Vera gel and vitamin $C$ (group $C$ and $D$, respectively) when compared with group $B$. The group induced with $\mathrm{AlCl}_{3}$ shows a decrease in sperm motile count when compared with other groups (Figure 4).

\section{Total sperm count}

Group A (control) presented an average Total Sperm Count (TSC) of $325.0 \pm 52.1 \times 106 \mathrm{~mL}$. Group B presented an average TSC of $171.0 \pm 55.1 \times 106 \mathrm{~mL}$. Group C presented an average TSC of $333.0 \pm 73.7 \times 106 \mathrm{~mL}$ while group $D$ presented an average TSC of $282.0 \pm 14.7 \times 106 \mathrm{~mL}$. There was a significant reduction $(p<0.005)$ in the group treated with $\mathrm{AlCl}_{3}$ (group $B)$ when compared with the control group. Groups treated with AVG and vitamin C (group C and D) shows a significant increase $(p<0.005)$ when compared with group B (Figure 5$)$. 


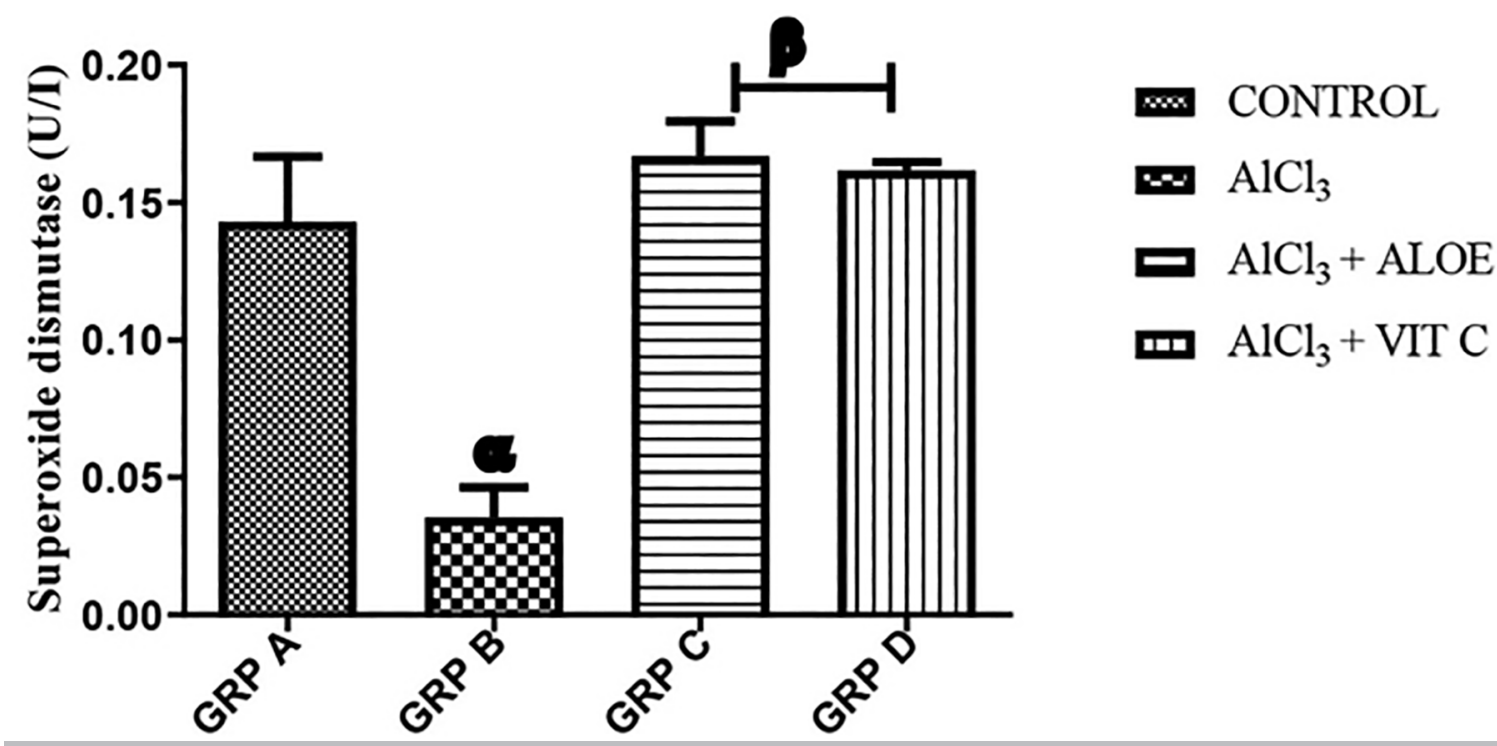

Figure 1. Graph showing serum SOD activity across the groups. Each value represents Mean $\pm S E M, n=5$

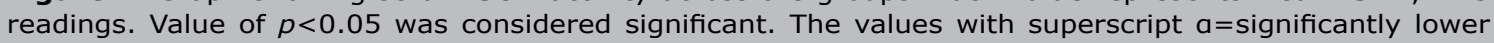
from group $A, \beta=$ significantly higher from group $B$. SOD - Superoxide Dismutase.

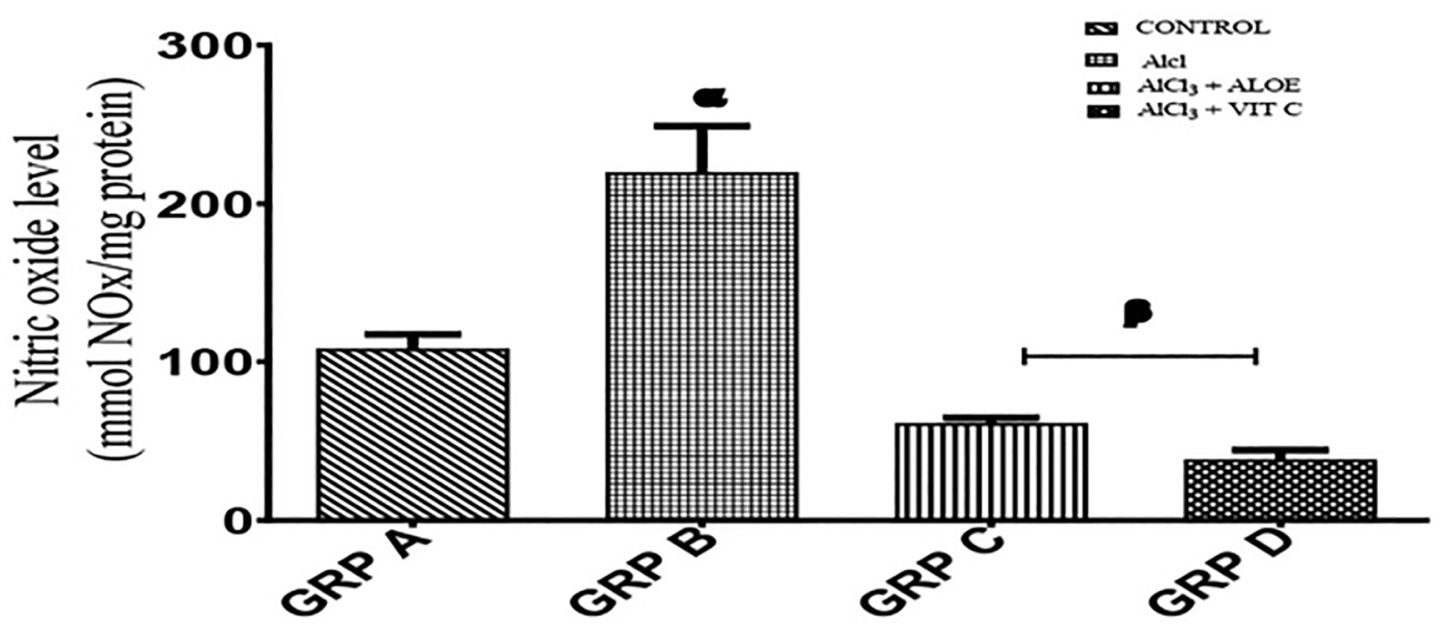

Figure 2. Graph showing serum NO activity across the groups. Each value represents Mean $+S E M, n=5$

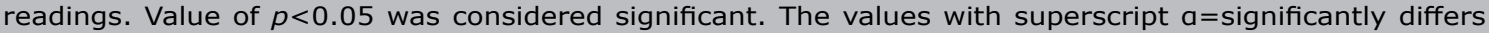
from group $A, \beta=$ significantly different from group B. NO - Nitric Oxide.

\section{Sperm concentration count}

Group A (control) presented an average Sperm Concentration Count (SCC) of 216.7 $\pm 35.1 \times 106 \mathrm{~mL}$. Group B presented an average SCC of $120.0 \pm 26.5 \times 106 \mathrm{~mL}$. Group C presented an average SCC of $205.0 \pm 20.8 \times 106 \mathrm{~mL}$ while group D presented an average SCC of $157.5 \pm 33.0 \times 106 \mathrm{~mL}$. Sperm concentration significantly reduced in the group treated with $\mathrm{AlCl}_{3}$ (group B) when compared with the control group. Groups treated with Aloe Vera gel and vitamin $C$ (groups $C$ and $D$ ) showed a significant increase $(p<0.005)$ when compared with group B (Figure 6).

\section{Sperm morphology}

There was a significant difference $(p<0.05)$ in sperm morphology in the treated groups ( $C \& D$ ) when compared to the group induced with $\mathrm{AlCl}_{3}$. The morphology recovery also appears to be treatmentdependent as group $\mathrm{C}$ was found to be significantly different from group D (Figure 7).

Sperm progressive assessment

There were higher fast movements in the group treated with Aloe Vera gel (group C), followed by group D treated 


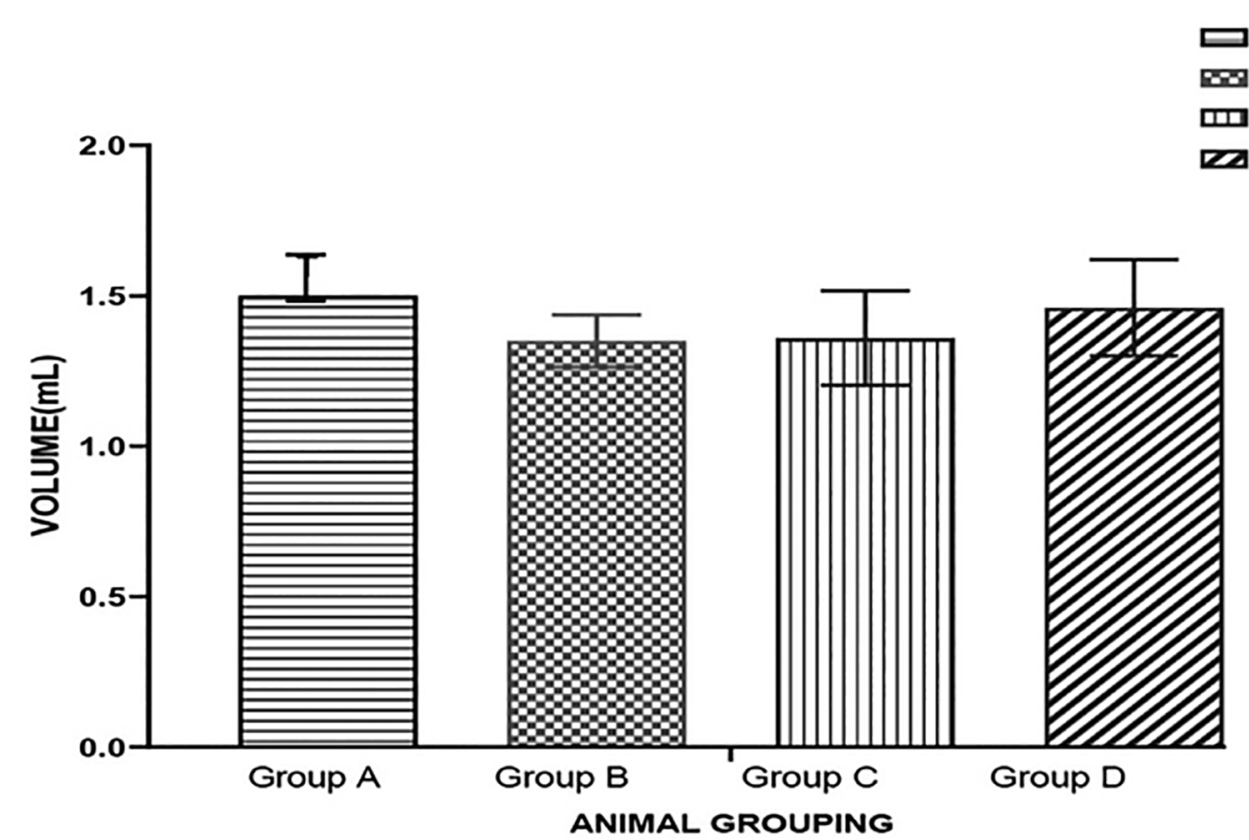

Figure 3. Graph showing sperm volume across the groups. Bars represent Mean \pm SEM. $p<0.05$. $n=5$. Each value represents Mean \pm SEM, $\mathrm{n}=5$ readings. Value of $p<0.05$ was considered significant.

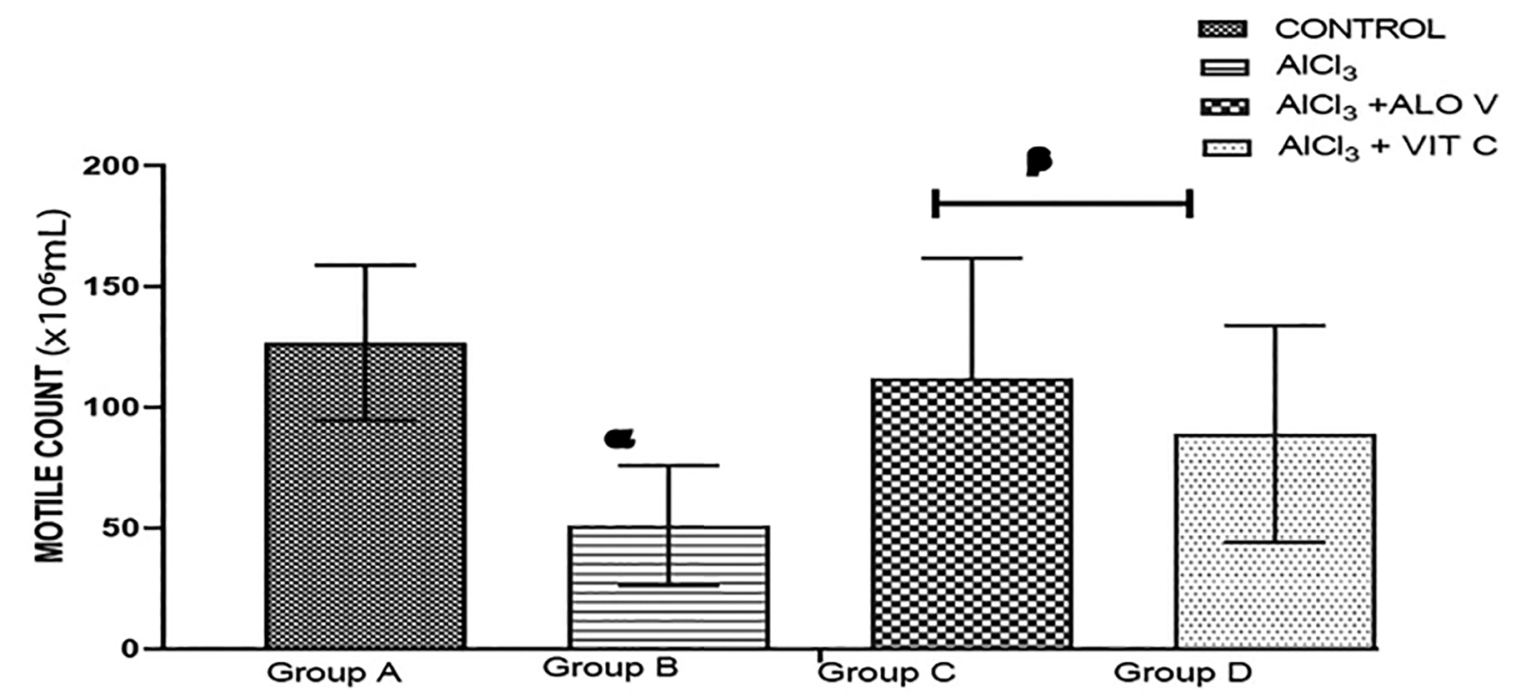

Figure 4. Graph showing the motile count of sperm cells across groups. Each value represents Mean+SEM, Value of $p<0.05$ was considered significant. Charts with superscript a (alpha) is significantly different from group $A$, superscript $\beta$ (beta) is significantly different from group $B$.

with vitamin $\mathrm{C}$. Slow movement was remarkably noticeable in group $\mathrm{B}$, induced with $\mathrm{AlCl}_{3}$ (Figure 8).

\section{DISCUSSION}

Heavy metals are considered dangerous substances causing health hazards to humans and animals through progressive irreversible accumulation in their bodies, because of repeated consumption of small amounts of these metals. Aluminum chloride is capable of damaging the organism in many ways, due to its high affinity to various tissues and its tendency to accumulate (Aitken \& Roman, 2008).
The present study revealed that the administration of Aloe vera gel protects against the damaging effects of $\mathrm{AlCl}_{3}$ on the histomorphological features of the testes. It was clearly observed that the group treated with AVG showed near normal testicular morphology and compares fairly well with Vitamin C, a known antioxidant. This is clearly demonstrated by the reversal of distorted histological architecture seen in the photomicrograph of AVG treated rats. This is in agreement with the findings in similar research, which reported that Aloe vera was effective in ameliorating histopathological changes in the 


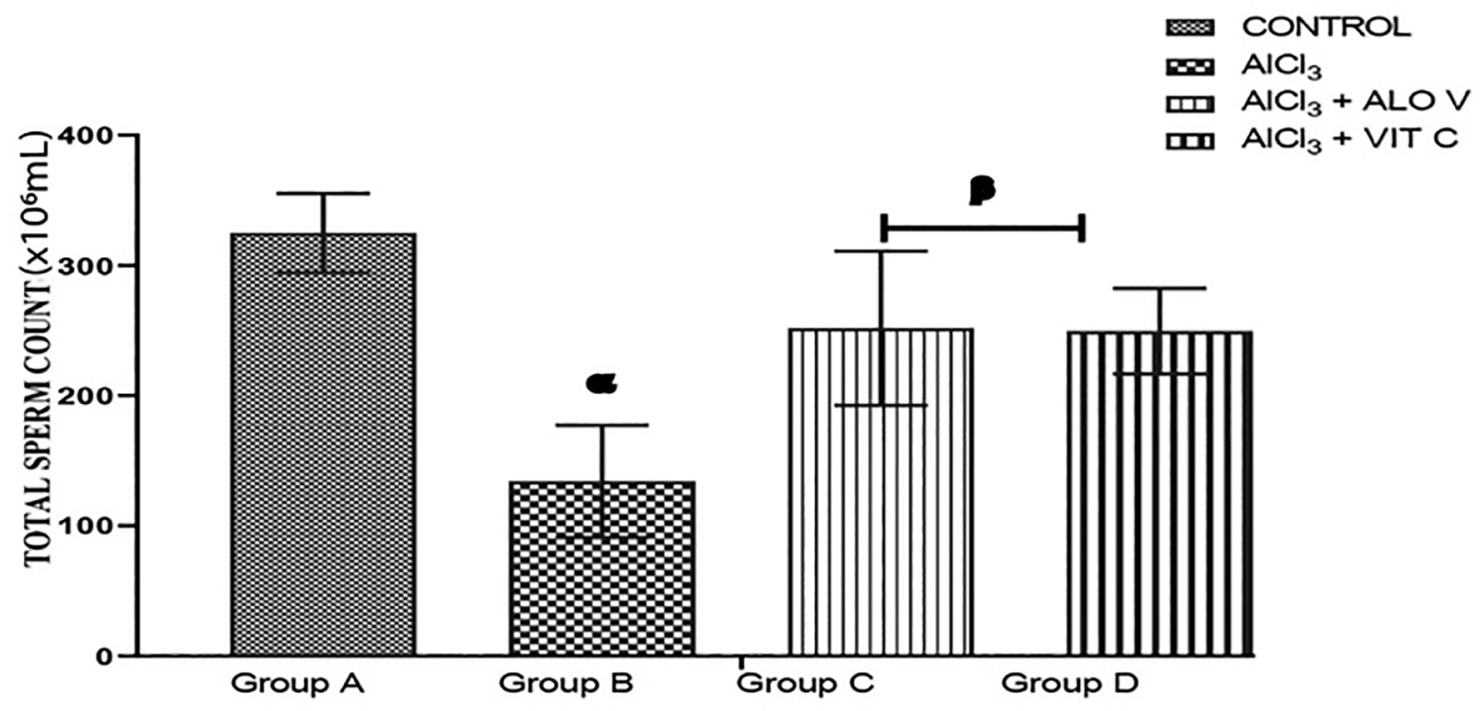

ANIMAL GROUPING

Figure 5. Graph showing the total sperm count across the groups. Each value represents Mean $\pm S E M$, $\mathrm{n}=5$ readings. A $p$ value $<0.05$ was considered significant. The values with superscript a are significantly different from group $A, \beta=$ significantly different from group $B$.

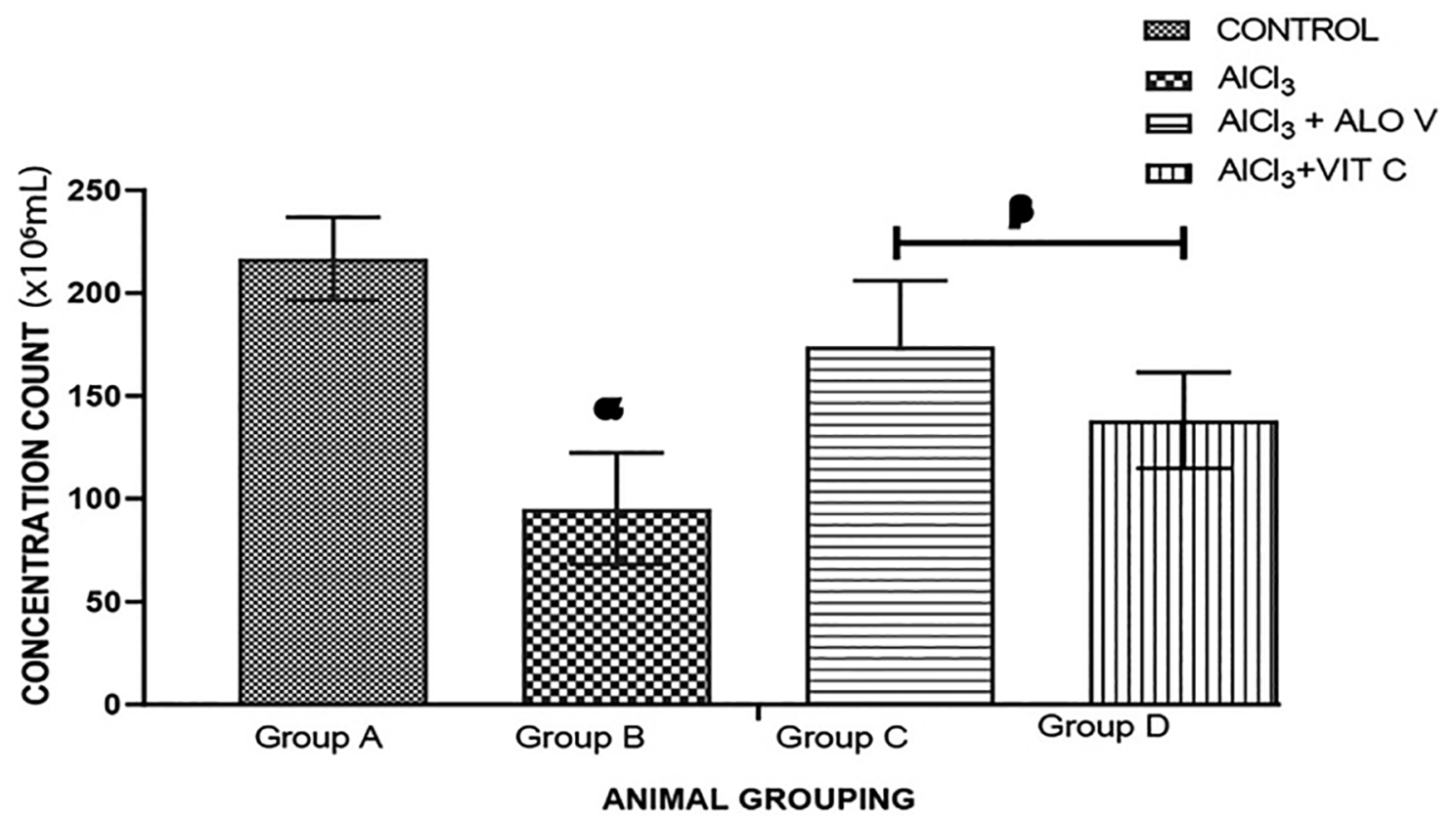

Figure 6. Graph showing sperm concentration count across the groups. Each value represents Mean $\pm \mathrm{SEM}$, $\mathrm{n}=4$ readings. A $p$ value $<0.05$ was considered significant. The values with superscript a are significantly different from group $A, \beta=$ significantly different from group $B$.

testes following bisphenol A induced testicular toxicity (Behmanesh et al., 2018).

Our findings in this study showed that aluminum chloride has negative effects on sperm motility, sperm count, viability, morphology and it increases the percentage of abnormal sperms. This finding is in support of past studies that aluminum chloride has the ability to reduce reproductive capacity (Guo et al., 2005b; Buraimoh et al., 2012). In the current study, results revealed that the accumulation of aluminum chloride in the body could be a predisposing factor to male infertility, as recorded in the semen parameters and sperm morphology. This is because the accumulation of aluminum chloride in the body can lead to elevated concentrations of aluminum chloride in the testes (Guo et al., 2002). In this study, we also observed that aloe vera gel attenuated the detrimental effects of 


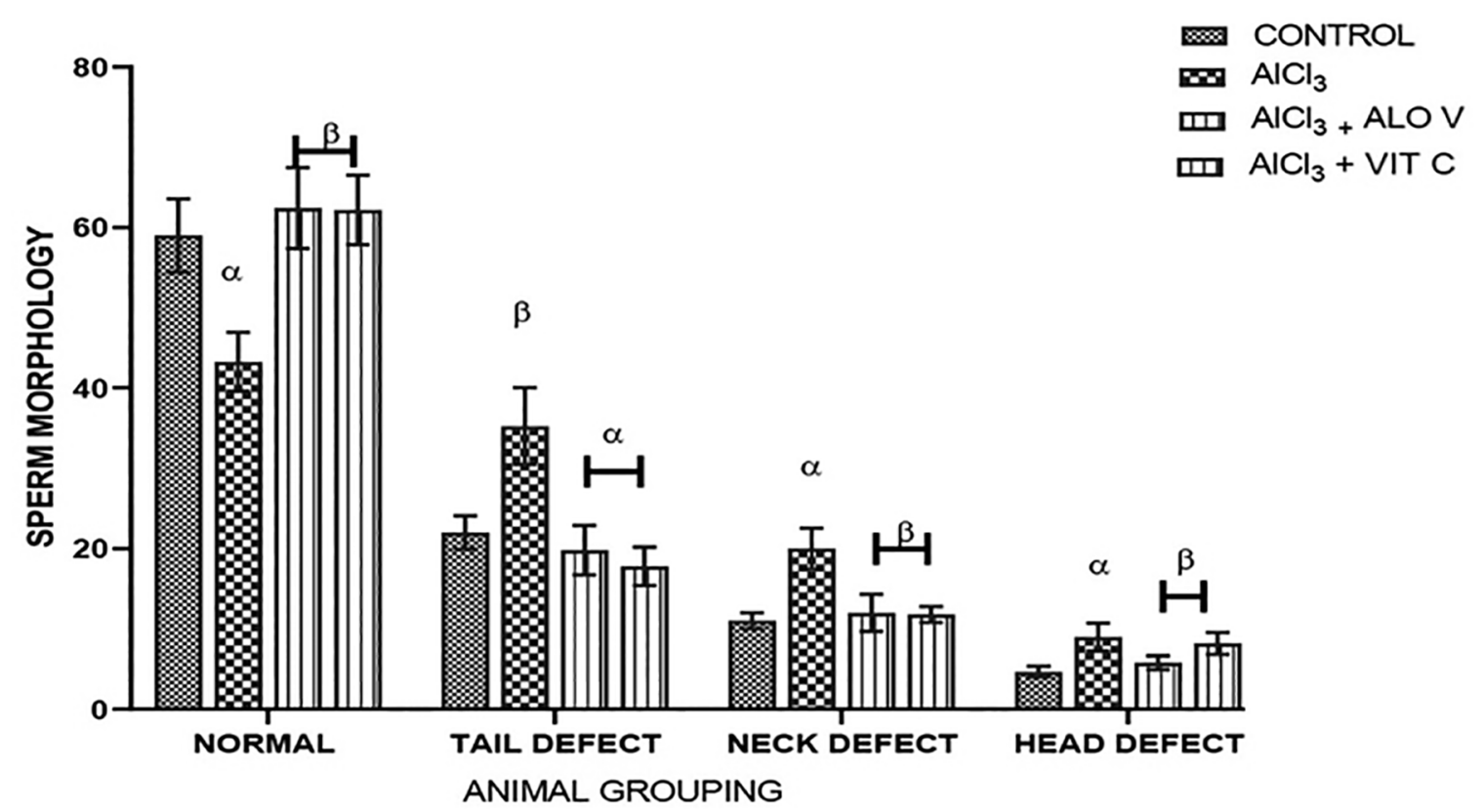

Figure 7. Graph shows the sperm morphology across the groups. Each value represents Mean $\pm \mathrm{SEM}, \mathrm{n}=$ 5 readings. A $p$ value $<0.05$ was considered significant. Effects of Aloe vera gel on sperm morphology. The values with superscript $a$ are significant different from Group A, $\beta=$ different from Group B

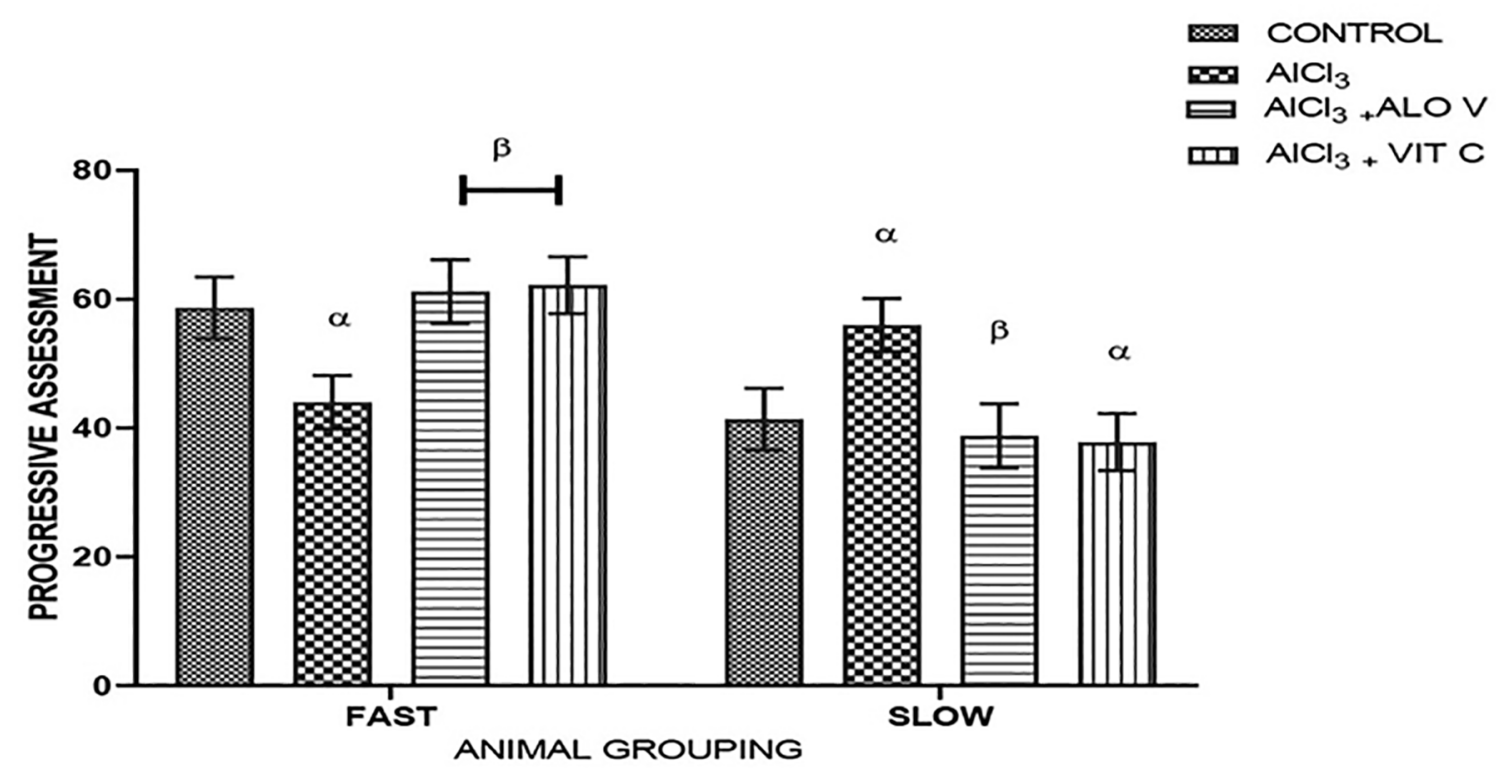

Figure 8. Graph showing the progressive assessment of the sperms across the groups. Each value represents Mean \pm SEM, $n=5$ readings, a $p$ value $<0.05$ was considered significant. The values with superscript a are significantly different from Group $A, \beta=$ different from Group $B$.

aluminum chloride on the semen parameters. Therefore, it is plausible to suggest that the effects of aloe vera gel on sperm volume, sperm motility, sperm counts and morphology could be partly mediated by its counteraction on oxidative stress within rat reproductive organs, via its antioxidant properties (Ikeno et al., 2002). The aluminum chloride administration with vitamin $\mathrm{C}$ treatment also attenuated testicular damage induced by aluminum chloride treatment, as shown by the normal sperm count, normal sperm morphology and low histopathological changes in comparison with the group that received aluminum chloride only (group B). The protective effect of vitamin $C$ is accompanied by normalization of antioxidant activity in testis (Muthu \& Krishnamoorthy, 2012). However, aloe vera gel demonstrates similar antioxidant properties when compared to vitamin $\mathrm{C}$.

In agreement with the report from Yousef \& Salama (2009), the results of this study showed that aluminum reduced superoxide dismutase (SOD) activity. SOD protects spermatozoa against spontaneous oxygen toxicity and lipid peroxidation. Since Reactive Oxygen Species (ROS) have been indicated to have a role in steroidogenesis and 
gametogenesis, the mentioned effects might have been responsible for the poor sperm quality seen in aluminumtreated rats. Aluminum can incite the oxidation of molecules in the body, thereby resulting in oxidative stress. Oxidative stress has been shown to play an important role in causing male infertility by inducing defects in sperm functions. Reactive oxygen species (ROS) are central to a host of pathologies, including inflammation, toxicity, and endocrine disruption by environmental chemicals, and are degraded by the organized system of antioxidants. ROS damages almost all macromolecules of the cell, causing impairment of cellular functions (Arumugam et al., 2014). Meanwhile, Aloe vera exhibits protective effects against oxidative damage by decreasing the levels of free radicals, through its free radical scavenging activity, particularly against oxygen radicals. Oxidative stress through the generation of ROS had been proposed as one of the possible mechanisms of aluminum chloride toxicity on male reproductive functions. It has been proven that aluminum chloride increased the production of ROS by increasing the generation of testicular hydrogen peroxide and hydroxyl radicals in experimental rats (Exley, 2004; Yousef \& Salama, 2009). Vitamin C treatment in this study prevents testicular damage and enhances sperm quality. Accumulating evidence suggests that the protective effect of vitamin $C$ against oxidative damage is due to its antioxidative properties (Wang et al., 2002). However, aloe vera gel improved the sperm quality by scavenging the ROS and enhanced testicular enzymatic antioxidant ability. The result of this study also shows that aluminum chloride significantly increased nitric oxide activity compared to the control and treated groups (groups A, C, and D) affirming the fact that it causes damage by inducing oxidative stress.

\section{CONCLUSION}

Based on the present study, we can conclude that aluminum chloride distorted testicular histo-architecture via altered reproductive biochemistry. The toxic effects induced by aluminum chloride were ameliorated after treatment with aloe vera gel. Aloe vera gel showed similar anti-oxidative properties when compared with ascorbic acid, a known anti-oxidant.

\section{ACKNOWLEDGMENT}

The authors wish to acknowledge the technical staff of the Department of Human Anatomy, the Federal University of Technology Akure for technical assistance during the course of the study.

\section{CONFLICT OF INTEREST}

The authors have no conflict of interest to declare.

\section{Corresponding author:}

Busuyi Kolade Akinola

Department of Anatomy

School of Health and Health Technology

Federal University of Technology

Akure, Nigeria.

Email: bkakinola@futa.edu.ng

\section{REFERENCES}

Aitken RJ, Roman SD. Antioxidant systems and oxidative stress in the testes. Oxid Med Cell Longev. 2008;1:15-24. PMID: 19794904 DOI: 10.4161/oxim.1.1.6843
Arumugam B, Manaharan T, Chua KH, Palanisamy UD. Antioxidant and antiglycemic potentials of a standardized extract of Syzygium malaccense. Food Sci Technol. 2014;59:707-12. DOI: 10.1016/j.Iwt.2014.06.041

Behmanesh MA, Najafzadehvarzi H, Poormoosavi SM. Protective effect of Aloe vera extract against bisphenol an induced testicular toxicity in Wistar rats. Cell J. 2018;20(2):278-83. PMID: 29633606 DOI: 10.22074/ cellj.2018.5256

Björndahl L, Söderlund I, Kvist U. Evaluation of the onestep eosin-nigrosin staining technique for human sperm vitality assessment. Hum Reprod. 2003;18:813-6. PMID: 12660276 DOI: 10.1093/humrep/deg199

Buraimoh AA, Ojo SA, Hambolu JO, Adebisi S. Effects of aluminium chloride exposure on the histology of the cerebral cortex of adult Wistar rats. J Biol Life Sci. 2012;3:87-113. DOI: 10.5296/jbls.v3i1.1421

Crosswhite FS, Crosswhite CD. Aloe vera plant symbolism and the threshing floor. Desert Plants. 1984;6:43-50.

Ekaluo UB, Ikpeme EV, Udokpoh AE. Sperm head abnormality and mutagenic effects of Aspirin, paracetamol and caffeinecontaining analgesics in rats. Internet J Toxicol. 2009;7:1-9.

Ekaluo UB, Udokpoh AE, Ikpeme EV, Peter EU. Effects of chloroquine treatments on sperm count and weight of testes in male rats. Global J Pure Appl Sci. 2008;14:175-8. DOI: $10.4314 /$ gjpas.v14i2.16793

Eshun K, He Q. Aloe vera: a valuable ingredient for the food, pharmaceutical and cosmetic industries--a review. Crit Rev Food Sci Nutr. 2004;44:91-6. PMID: 15116756 DOI: $10.1080 / 10408690490424694$

Exley C. The pro-oxidant activity of aluminum. Free Radic Biol Med. 2004;36:380-7. PMID: 15036357 DOI: 10.1016/j.freeradbiomed.2003.11.017

Guo $\mathrm{CH}$, Huang $\mathrm{CJ}$, Chiou $\mathrm{YL}$, Hsu GS. Alteration of trace element distribution and testis ACE activity in mice with high peritoneal aluminum. Biol Trace Elem Res. 2002;86:14557. PMID: 12008977 DOI: $10.1385 / B T E R: 86: 2: 145$

Guo $\mathrm{CH}$, Lin $\mathrm{CY}$, Yeh MS, Hsu GS. Aluminum-induced suppression of testosterone through nitric oxide production in male mice. Environ Toxicol Pharmacol. 2005;19:33-40. PMID: 21783460 DOI: $10.1016 /$ j.etap.2004.02.009

Guo $\mathrm{CH}$, Lu YF, Hsu GS. The influence of aluminum exposure on male reproduction and offspring in mice. Environ Toxicol Pharmacol. 2005;20:135-41. PMID: 21783580 DOI: 10.1016/j.etap.2004.11.007

Gupta PC, Verma A. Potential parameters in assessment of testicular toxicity. Biomed J Sci Tech Res. 2018;7:5915-8. DOI: 10.26717/BJSTR.2018.07.001504

Hamman $\mathrm{JH}$. Composition and applications of Aloe vera leaf gel. Molecules. 2008;13:1599-616. PMID: 18794775 DOI: $10.3390 /$ molecules 13081599 
Ikeno Y, Hubbard GB, Lee S, Yu BP, Herlihy JT. The influence of long-term Aloe vera ingestion on age-related disease in male Fischer 344 rats. Phytother Res. 2002;16:712-8. PMID: 12458471 DOI: $10.1002 /$ ptr. 1022

Jiang HX, Chen LS, Zheng JG, Han S, Tang N, Smith BR. Aluminum-induced effects on Photosystem II photochemistry in citrus leaves assessed by the chlorophyll a fluorescence transient. Tree Physiol. 2008;28:1863-71. PMID: 19193569 DOI: 10.1093/treephys/28.12.1863

Kumar N, Singh AK. Trends of male factor infertility, an important cause of infertility: a review of literature. J Hum Reprod Sci. 2015;8:191-6. PMID: 26752853 DOI: $10.4103 / 0974-1208.170370$

Liu Q, Lei Z, Huang A, Lu Q, Wang X, Ahmed S, Awais I, Yuan Z. Mechanisms of the testis toxicity induced by chronic exposure to mequindox. Front Pharmacol. 2017;8:679. PMID: 29018347 DOI: 10.3389/fphar.2017.00679

Misra HP, Fridovich I. The role of superoxide anion in the autoxidation of epinephrine and a simple assay for superoxide dismutase. J Biol Chem. 1972;247:3170-5. PMID: 4623845

Moshage $H$, Kok $B$, Huizenga JR, Jansen PL. Nitrite and nitrate determinations in plasma: a critical evaluation. Clin Chem. 1995;41:892-6. PMID: 7768008 DOI: 10.1093/ clinchem/41.6.892

Muthu K, Krishnamoorthy P. Effect of vitamin C and vitamin $\mathrm{E}$ on mercuric chloride-induced reproductive toxicity in male rats. Biochem Pharmacol. 2012;1(7):e1000102.

National Research Council (US); Committee for the Update of the Guide for the Care and Use of Laboratory Animals. Guide for the care and use of laboratory animals. 8th ed. Washington: The National Academies Press; 2011.

Nayak P. Aluminum: impacts and disease. Environ Res. 2002;89:101-15. PMID: 12123643 DOI: 10.1006/ enrs.2002.4352
Nwajo HU. Antioxidant activity of the exudate from Aloe barbadensis leaves in diabetic rats. Biokemistri. 2006;18:77-81. DOI: 10.4314/biokem.v18i2.56395

Pandey G, Jain GC. A review on toxic effects of aluminum exposure on male reproductive system and probable mechanisms of toxicity. Int J Toxicol Appl Pharmacol. 2013;3:48-57. PMID: 28868838 DOI: 10.22074/ ijfs. 2017.4859

Reynolds T, Dweck AC. Aloe vera leaf gel: a review update. J Ethnopharmacol. 1999;68:3-37. PMID: 10624859 DOI: $10.1016 / \mathrm{S} 0378-8741(99) 00085-9$

Sharma S, Sharma RK, Sharma R, Sharma A, Rai AK, Gupta RS, Singh Y. Synthesis and characterisation of some new aluminum derivatives of Schiff bases containing $\mathrm{N}, \mathrm{O}$ and $\mathrm{S}$ donor atoms and the anti fertility activity of the derivative $\mathrm{Al}[\mathrm{SC} 6 \mathrm{H} 4 \mathrm{~N}: \mathrm{C}(\mathrm{CH} 3) \mathrm{CH} 2 \mathrm{COCH} 3] 3$. Bioinorg Chem Appl. 2002;1:215-25. PMID: 18365055 DOI: $10.1155 /$ S1565363303000177

Surjushe A, Vasani R, Saple DG. Aloe vera: a short review. Indian J Dermatol. 2008;53:163-6. PMID: 19882025 DOI: $10.4103 / 0019-5154.44785$

Wang $M$, Chen JT, Ruan DY, Xu YZ. The influence of developmental period of aluminum exposure on synaptic plasticity in the adult rat dentate gyrus in vivo. Neuroscience. 2002;113:411-9. PMID: 12127098 DOI: $10.1016 / \mathrm{S} 0306-4522(02) 00193-8$

Yousef MI, Kamel KI, El-Guendi MI, El-Demerdash FM. An in vitro study on reproductive toxicity of aluminum chloride on rabbit sperm: the protective role of some antioxidants. Toxicology. 2007;239:213-23. PMID: 17714845 DOI: 10.1016/j.tox.2007.07.011

Yousef MI, Salama AF. Propolis protection from reproductive toxicity caused by aluminum chloride in male rats. Food Chem Toxicol. 2009;47:1168-75. PMID: 19425234 DOI: 10.1016/j.fct.2009.02.006 